\title{
Randomized, masked, in vitro comparison of three commercially available tear film osmometers
}

This article was published in the following Dove Press journal:

Clinical Ophthalmology

27 January 2017

Number of times this article has been viewed

\author{
Guillermo Rocha' \\ Eric Gulliver' \\ Armand Borovik ${ }^{2}$ \\ Clara C Chan ${ }^{2}$ \\ 'Department of Ophthalmology, \\ University of Manitoba, Winnipeg, \\ ${ }^{2}$ Department of Ophthalmology and \\ Vision Sciences, University of Toronto, \\ Toronto, Ontario, Canada
}

Purpose: The purpose of this study was to compare the precision and accuracy of commercially available tear film osmometers.

Methods: Contrived tear solution target values representing the physiological range of tear osmolarity (normal eyes $297 \mathrm{mOsm} / \mathrm{L}$, moderately dry eyes $342 \mathrm{mOsm} / \mathrm{L}$, and severe dry eyes $383 \mathrm{mOsm} / \mathrm{L}$ ) were constructed using a mix of mono- and divalent electrolytes, metabolites, serum albumin, and $\mathrm{pH}$ balanced to 7.4. Solution values were randomized and masked from the investigators during testing. Osmometers (Wescor 5520 Vapro Pressure Osmometer: device A, TearLab Osmolarity System: device B, and i-Med Pharma i-Pen: device C) were calibrated according to manufacturer instructions. Each level was tested $64 \times$ on each osmometer across two sites. Accuracy was reported as a correlation coefficient against expected linear dilutions, precision was calculated as percent coefficient of variation.

Results: Device A reported a correlation with known solutions of $r^{2}=0.98$, with averages of $305.6 \pm 4.0,352.2 \pm 5.5$, and $389.8 \pm 4.0 \mathrm{mOsm} / \mathrm{L}$, and coefficient of variations $(\mathrm{CVs})$ of $1.3 \%, 1.6 \%$, and $1.0 \%$, respectively. Device B reported an $r^{2}=0.96$, with averages of $300.6 \pm 3.7,341.4 \pm 7.9$, and $376.8 \pm 5.1 \mathrm{mOsm} / \mathrm{L}$, and CVs of $1.2 \%, 2.3 \%$, and $1.4 \%$, respectively. Device C reported an $r^{2}=0.03$, with averages of $336.4 \pm 21.5,342.0 \pm 20.7$, and $345.7 \pm 22.0 \mathrm{mOsm} / \mathrm{L}$, and $\mathrm{CVs}$ of $6.4 \%, 6.1 \%$, and $6.4 \%$, respectively.

Conclusion: In this randomized, masked, in vitro study, device A and device B had significantly better accuracy and precision in measuring osmolarity of contrived tear solutions of known target values compared to device C. Device $\mathrm{C}$ showed insufficient performance to accurately and precisely delineate osmolarity levels in the physiological range. Furthermore, in vivo studies would be required to compare performance in human subjects.

Keywords: tear osmolarity, TearLab Osmometer, i-Pen Osmometer, electrical impedance, Wescor Osmometer, precision

\section{Introduction}

Dry eye disease (DED) is a multifactorial disease of the tears and ocular surface that results in symptoms of discomfort, visual disturbance, and tear film instability with potential damage to the ocular surface. It is accompanied by increased osmolarity of the tear film and inflammation of the ocular surface. ${ }^{1}$ According to the 2007 TFOS DEWS report, tear osmolarity and tear instability are recognized as core mechanisms of the disease. ${ }^{1}$ Osmolarity above the homeostatic range causes damage to the ocular surface, a loss of goblet cells, disturbance of mucin expression and initiates a release of inflammatory mediators into the tears. ${ }^{1}$ As a global marker for DED, tear osmolarity is known to increase in both aqueous deficient and evaporative dry eye, correlates with disease severity, and is superior in overall accuracy to any other single test for dry eye diagnosis. ${ }^{2-5}$ Furthermore, it is a useful metric to monitor disease course after a specific treatment in the clinic and in clinical trials. ${ }^{6-10}$ 
Measurement of tear osmolarity, however, is a nontrivial exercise. The volume of tear fluid available for analysis in a dry eye patient is well below the $\sim 10 \mu \mathrm{L}$ volume required by traditional laboratory osmometers. Although, the osmolarity on the central cornea has been theorized to transiently attain levels upward of $1,000 \mathrm{mOsm} / \mathrm{L}^{11}$ the physiological range of tear osmolarity in the lower meniscus is highly compressed, ranging from 275 to $400 \mathrm{mOsm} / \mathrm{L}{ }^{3}$ Clinically, relevant differences of $\sim 11 \mathrm{mOsm} / \mathrm{L}$ indicate a therapeutic change, ${ }^{12}$ while the expected difference between mean values of normal and DED patients is $\sim 20 \mathrm{mOsm} / \mathrm{L},{ }^{13}$ and inter-eye differences of $\geq 8 \mathrm{mOsm} / \mathrm{L}$ are considered diagnostic of tear film instability. ${ }^{14}$ Accordingly, tear osmometers require a high degree of precision and accuracy.

This study compares the analytical performance of three commercially available devices: Wescor 5520 Vapro Pressure Osmometer (Wescor Inc, Logan, UT, USA - device A), TearLab Osmolarity System (TearLab Corp, San Diego, CA, USA - device B), and i-Pen (i-Med Pharma, Dollard-desOrmeaux, Quebec, Canada - device C). Device A works by measuring the electrical resistance of a thermocouple, on which fluid condenses and changes the local temperature when exposed to the sample fluid. Device B and Device C, per their respective manufacturer's instruction manual, work by measuring electrical impedance and have been commercialized as point-of-care diagnostics.

\section{Methods}

Contrived tear solution target values representing the physiological range of tear osmolarity (normal $297 \mathrm{mOsm} / \mathrm{L}$, moderate $342 \mathrm{mOsm} / \mathrm{L}$, and severe $383 \mathrm{mOsm} / \mathrm{L}$ ) were constructed using a mix of mono- and divalent electrolytes, metabolites, serum albumin and were balanced using $\mathrm{NaOH}$ and $\mathrm{HCl}$ to $\mathrm{pH}$ 7.4. Specifically, sodium chloride (165 mM), potassium chloride (32 $\mathrm{mM})$, sodium bicarbonate $(49 \mathrm{mM})$, sodium phosphate monobasic $(5 \mathrm{mM})$, sodium phosphate dibasic $(6 \mathrm{mM})$, urea $(10 \mathrm{mM})$, bovine serum albumin $(0.15 \mathrm{mM})$ were mixed to a final osmolarity of $479 \pm 1.6$, as measured on device A. Dilutions of $61.9 \%, 71.4 \%$, and $80.0 \%$ resulted in an expected osmolarity of 297,342 , and $383 \mathrm{mOsm} / \mathrm{L}$, respectively, representing the normal, moderate, and severe ranges in DED. Similar contrived tear fluid formulations have been used in US Food and Drug Administration submissions as valid surrogates for determining the performance of osmometers. ${ }^{15}$

At each day of testing, device A was calibrated according to manufacturer instructions using National Institute of Standards and Technology (NIST) traceable sodium chloride.
The factory calibration of device B was verified each day of testing using manufacturer supplied electronic controls as well as NIST traceable sodium chloride. No calibration was performed for device $\mathrm{C}$ as per the user instruction manual.

Solution values were randomized and masked from the investigators during testing. Investigators were trained in clinical ophthalmology, but were not intimately familiar with the osmolarity devices under test. For device A, a $20 \mu \mathrm{L}$ sample of contrived tear was pipetted onto a pre-cut piece of filter paper loaded in the machine. For device $B$ and device $\mathrm{C}, 0.5 \mathrm{~mL}$ microcentrifuge tubes containing contrived tears of varying osmolarity levels were inverted to collect a small volume of fluid in the cap. After opening the microcentrifuge tube, the tip of each device was placed gently atop the fluid residing in the cap. Care was taken not to immerse the tips of the sensors into the fluid according to manufacturers recommended procedures. Contrived tear levels were tested $64 \times$ on each of the three osmometers across two sites, as 64 readings per device would be required to detect a difference of $8 \pm 8 \mathrm{mOsm} / \mathrm{L}$ between the devices at an alpha error $=0.05$ to provide a study power of $90 \%$. Temperature was recorded throughout testing and was maintained between $21^{\circ} \mathrm{C}$ and $25^{\circ} \mathrm{C}$. Data were tested for normality using the Kolmogorov-Smirnov test. The statistical analysis of accuracy was estimated as a correlation coefficient against expected osmolarity to provide an unbiased reference for each of the three devices. Given the compressed dynamic range of tear osmolarity, low precision devices will have a very poor correlation coefficient $\left(r^{2}<0.5\right)$ in this experiment, whereas devices with $r^{2}>0.7-0.8$ will likely be sufficient for therapeutic tracking. The inclusion of device A provides a convenient metric by which to gauge high quality performance. Second, a Bland-Altman analysis for both point-ofcare devices (device B and device $\mathrm{C}$ ) was performed using expected osmolarity as a reference, where the difference from expected is plotted as the dependent variable, and descriptive statistics of these deviations presented. Precision was calculated as percent coefficient of variation (ratio of the standard deviation to the sample mean) as measured against theoretical dilutions, as well as the $95 \%$ confidence intervals on the Bland-Altman deviations. Note that as these were prepared samples with a fixed dynamic range, coefficients of variation allow direct comparison of precision.

\section{Results}

All data measured at each level across each osmometer were normally distributed using the Kolmogorov-Smirnov test $(P>0.10)$. Descriptive statistics for each osmometer are 
Table I Combined osmolarity data on contrived tear solutions for device A, device $B$, and device $C$ osmometers

\begin{tabular}{lcll}
\hline Level & Device A & Device B & Device C \\
\hline \multicolumn{2}{l}{ Measured osmolarity mean (mOsm/L) } & & \\
I $(297)$ & 305.6 & 300.6 & 336.4 \\
$2(342)$ & 352.2 & 341.4 & 342.0 \\
$3(383)$ & 389.8 & 376.8 & 345.7 \\
Standard deviation (mOsm/L) & & \\
I & 4.0 & 3.7 & 21.5 \\
2 & 5.5 & 7.9 & 20.7 \\
3 & 4.0 & 5.1 & 22.0 \\
Coefficient of variation (\%) & & \\
I & 1.3 & 1.2 & 6.4 \\
2 & 1.6 & 2.3 & 6.1 \\
3 & 1.0 & 1.4 & 6.4 \\
\hline
\end{tabular}

Note: Wescor 5520 Vapro Pressure Osmometer: device A; TearLab Osmolarity System: device B; and i-Med Pharma i-Pen: device C.

reported in Table 1. As shown in Figure 1, device A reported a linear regression of $0.98 x+16.7$ against estimated osmolarity with an $r^{2}=0.98$, with averages of $305.6 \pm 4.0,352.2 \pm 5.5$, and $389.8 \pm 4.0 \mathrm{mOsm} / \mathrm{L}$, and $\mathrm{CVs}$ of $1.3 \%, 1.6 \%$, and $1.0 \%$, respectively. As shown in Figure 2, device B reported a linear regression of $0.88 x+38.2$ against estimated osmolarity an $r^{2}=0.96$, with averages of $300.6 \pm 3.7,341.4 \pm 7.9$, and $376.8 \pm 5.1 \mathrm{mOsm} / \mathrm{L}$, and CVs of $1.2 \%, 2.3 \%$, and $1.4 \%$, respectively. As shown in Figure 3, device $\mathrm{C}$ reported a linear regression of $0.11 x+304.77$ against estimated osmolarity an $r^{2}=0.03$, with averages of $336.4 \pm 21.5,342.0 \pm 20.7$, and $345.7 \pm 22.0 \mathrm{mOsm} / \mathrm{L}$, and CVs of $6.4 \%, 6.1 \%$, and $6.4 \%$, respectively. When device A was used as a reference standard in Figure 4, device B reported a linear regression of $0.90 x+26.5$ with an $r^{2}=0.96$, while device $C$ reported a linear regression of $0.12 x+300.2$ with an $r^{2}=0.03$.

The Bland-Altman analysis shown in Figure 5 revealed that the average deviation of device $\mathrm{B}$ was $-1.6 \pm 7.1 \mathrm{mOsm} / \mathrm{L}$

Device A

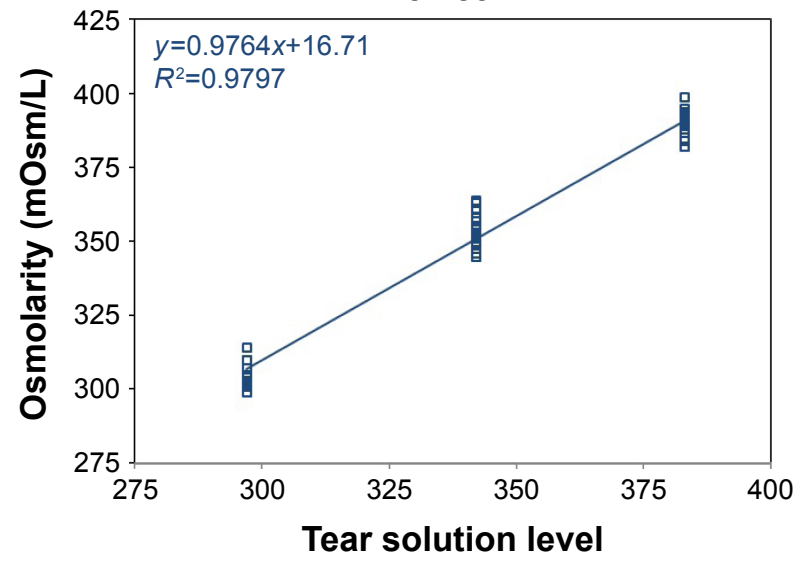

Figure I Device A osmometer readings vs ideal dilution osmolarity. Note: Wescor 5520 Vapro Pressure Osmometer: device A.

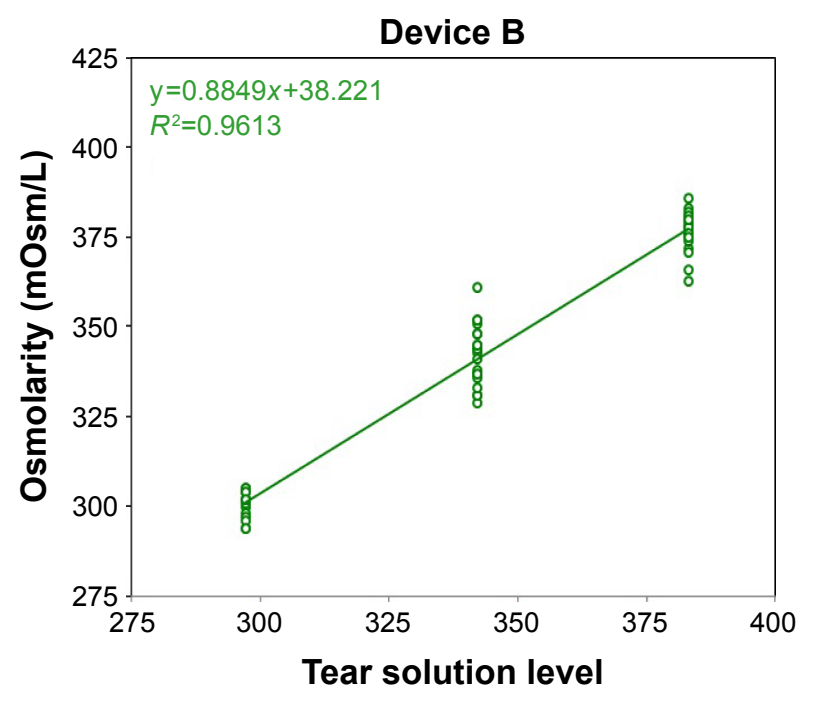

Figure 2 Device B osmometer readings vs ideal dilution osmolarity. Note: TearLab Osmolarity System: device B.

from theoretical, with a range of -20 to $+19 \mathrm{mOsm} / \mathrm{L}$, while device $\mathrm{C}$ (Figure 6) had a deviation of $-4.1 \pm 36.7 \mathrm{mOsm} / \mathrm{L}$ with a range of -91 to $+70 \mathrm{mOsm} / \mathrm{L}$. On an absolute scale, device $\mathrm{B}$ had $88 \%(56 / 64)$ measurements within $10 \mathrm{mOsm} / \mathrm{L}$ from target, while device $\mathrm{C}$ had only $15 \%$ (10/64) within $10 \mathrm{mOsm} / \mathrm{L}$. Of note, the precision of device B was far better in the low range close to the clinical cutoff, with a standard deviation of $\pm 3.7 \mathrm{mOsm} / \mathrm{L}$ in that category. Device $\mathrm{C}$ remained imprecise in that range, with a standard deviation of $\pm 21.5 \mathrm{mOsm} / \mathrm{L}$ at the low end. Figure 7 shows a histogram of the deviations from ideal for each device.

\section{Discussion}

Elevated tear osmolarity is known to be a central pathogenic cause of ocular surface damage ${ }^{1}$ and is regarded to be a

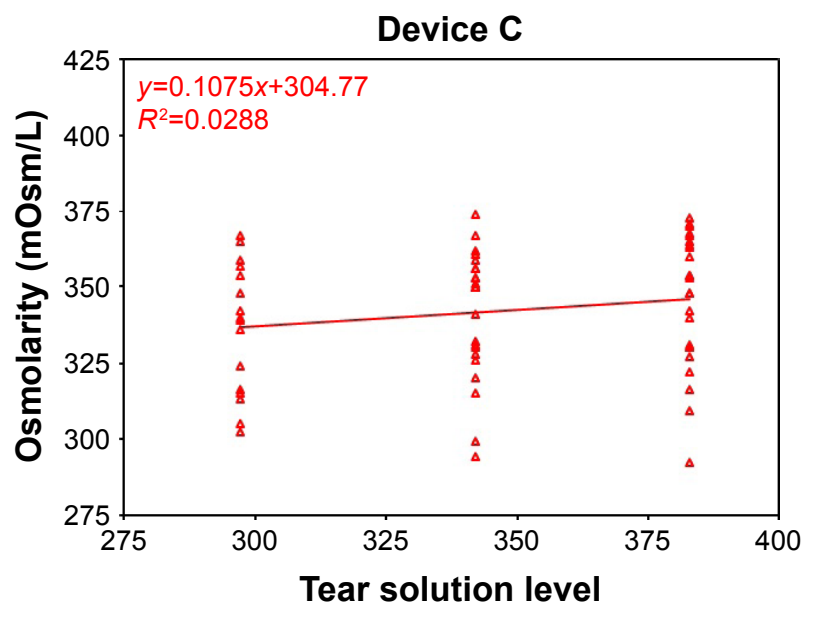

Figure 3 Device $C$ osmometer readings vs ideal dilution osmolarity. Note: i-Med Pharma i-Pen: device C. 


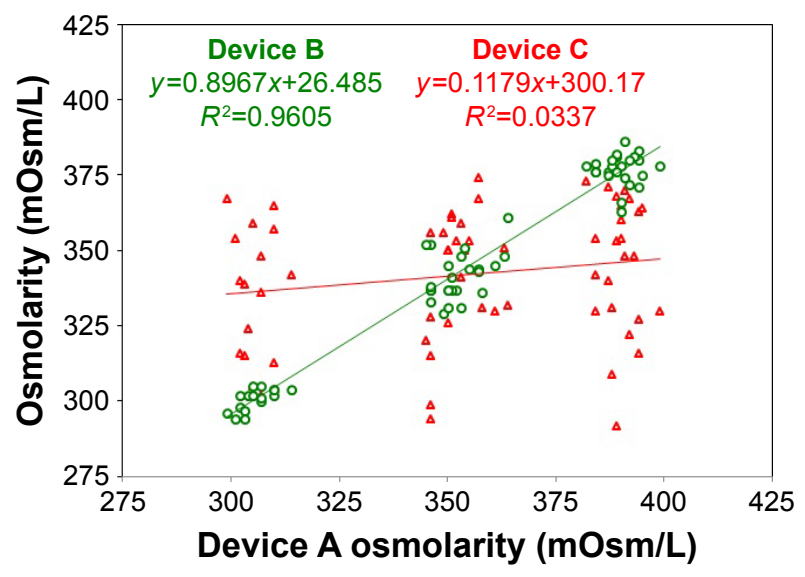

Figure 4 Device $B$ and device $C$ osmometers vs device A measured osmolarity. Note: Wescor 5520 Vapro Pressure Osmometer: device A; TearLab Osmolarity System: device B; and i-Med Pharma i-Pen: device C.

medically necessary test to assist in the diagnosis of DED. Because of the confounding nature of nerve damage due to hyperosmolarity ${ }^{16}$ a clinician cannot rely upon symptoms or other clinical signs to determine who in fact, has hyperosmolarity, and whether or not the cornea is under physiological stress as a result. Accordingly, the measurement of tear osmolarity is necessary to fully understand the severity of dry eye and the status of the ocular surface. ${ }^{3}$ Yet, because of the relatively compressed dynamic range and low volume of tear fluid available, high precision meters $(\sim<2.5 \% \mathrm{CV})$ that measure nanoliter volumes of tear fluid are required to properly assess tear film osmolarity.

Device A, being a laboratory osmometer, requires $10 \mu \mathrm{L}$ of tear, and is not considered viable as a point-of-care instrument, but serves as a reference for this study. Device A and the point-of-care nanoliter device $\mathrm{B}$ had similar performance

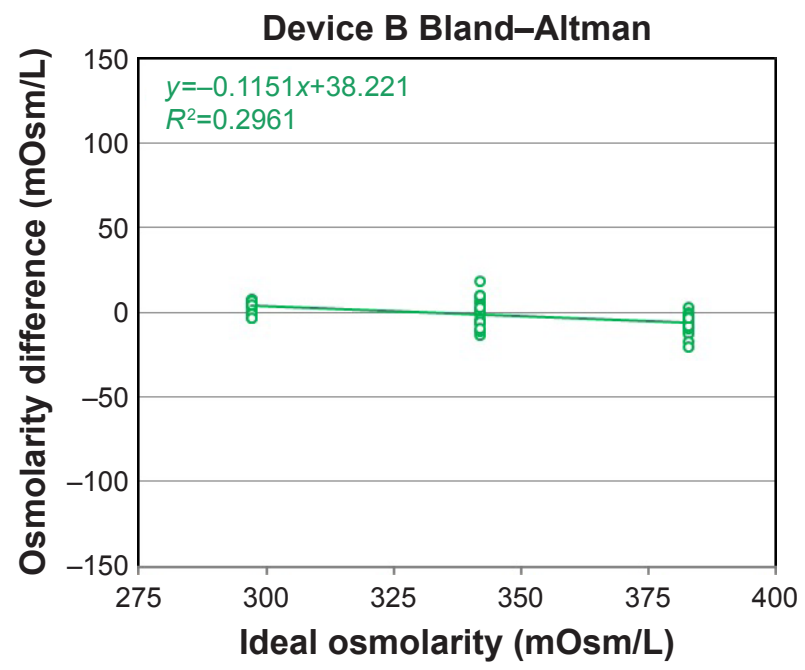

Figure 5 Bland-Altman plot for device B. Note: TearLab Osmolarity System: device B.

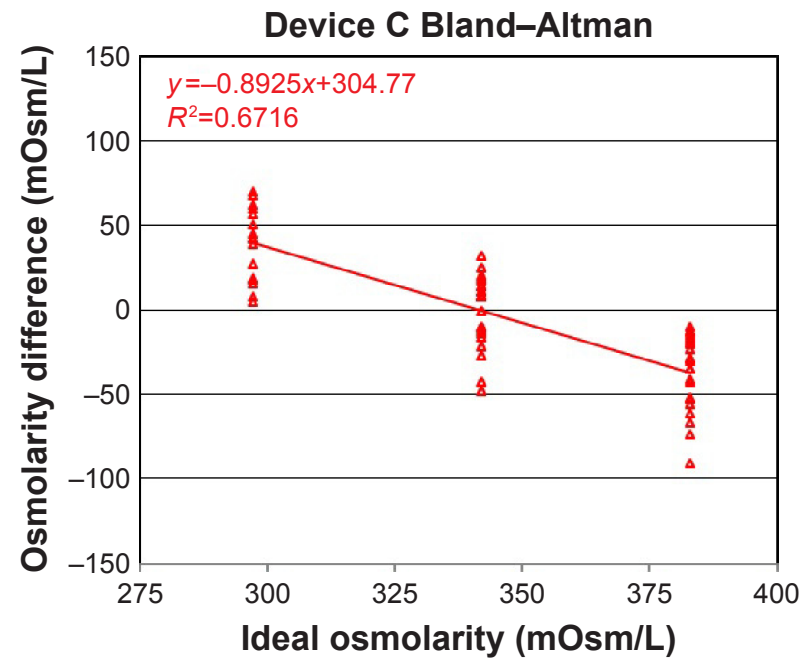

Figure 6 Bland-Altman plot for device $C$. Note: i-Med Pharma i-Pen: device C.

and sufficient resolution to accurately and precisely delineate osmolarity levels consistent with normal, moderately dry, and severely dry eyes. The study data are consistent with previous analysis of device $\mathrm{B}$, which showed a regression of $y=0.98 x+6.51$, with an $r^{2}=0.95$ from untrained users of the device, with total coefficients of variation ranging from $1.87 \%$ to $2.47 \% .{ }^{17}$ Another published study comparing device A to device $\mathrm{B}$ found a $r^{2}=0.9$ correlation with a slightly higher standard deviation $\pm 9.4 \mathrm{mOsm} / \mathrm{L}$ than this study, ${ }^{18}$ although the interpretation was similar; that device A and device B have concordance on tear samples. These data also support independent studies on human tear samples that compared device $\mathrm{B}$ to the Clifton freezing point depression osmometer, wherein the majority of test results fell within $95 \%$ confidence limits and absolute values differed by $<1 \% .{ }^{19}$

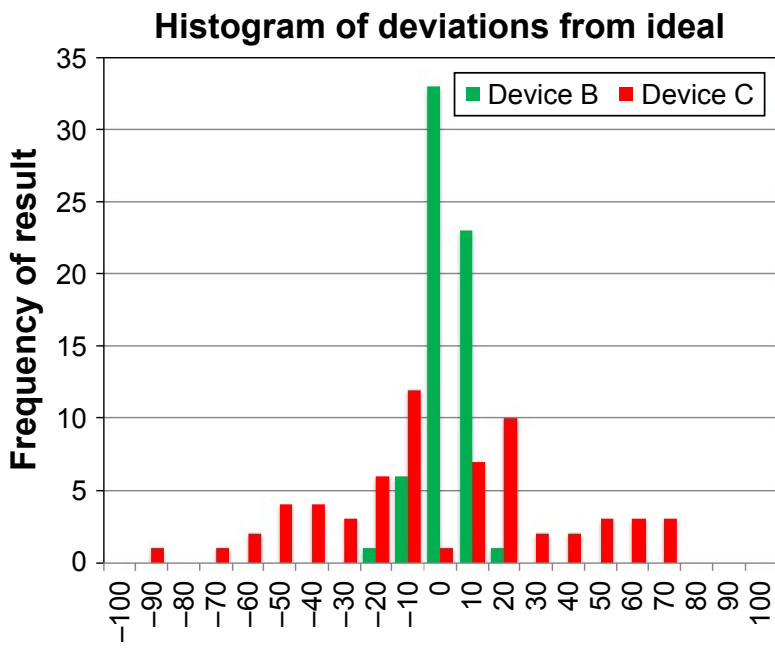

Difference from theoretical (mOsm/L)

Figure 7 Distribution of deviation from ideal osmolarity values. Note: TearLab Osmolarity System: device B; and i-Med Pharma i-Pen: device C. 
In this in vitro study, device $\mathrm{C}$ was significantly less accurate and less precise in its ability to identify osmolarity levels. Essentially, device $\mathrm{C}$ showed no relationship between the osmolarity of the standard solution and the results it produced. The data had a large spread across the measurement range, as demonstrated by the low correlation coefficient $\left(r^{2}=0.03\right)$ and significant overlap between the levels. The user manual for device $\mathrm{C}$ states that its intended use is

for the quantitative measurement of osmolarity (concentration of dissolved, active particles in tissue immersed in solution) of human tears in normal and Dry Eye Disease patients. ${ }^{20}$

The manual also provides reference data on tear osmolarity that matches generally accepted ranges for human tear osmolarity levels, ${ }^{3}$ including a normal average of $302 \mathrm{mOsm} / \mathrm{L}$, $327 \mathrm{mOsm} / \mathrm{L}$ for dry eye, and a full range between 275 and $400 \mathrm{mOsm} / \mathrm{L} .{ }^{20}$ One hypothesis as to why there was such a difference between device $\mathrm{C}$ and other osmometers (device $\mathrm{A}$ and device B) tested in this study is that the solution resistance values measured in this study (without any tissue presence) are not representative of the impedance values of ocular tissues immersed in solution. However, since the impedance of ocular surface tissues should be far higher than the impedance of tears, ${ }^{21}$ this hypothesis does not fully explain why the device returns values within the expected range of tear osmolarity. The conductivity of the contrived tear solutions was constructed to match that of tear fluid. It is perhaps the case that the measurement of conjunctival tissue in vivo represents a fundamentally different impedance system than the one studied here. Yet if that is the intended use of device $C$, it leads one to question the inescapable in vivo scenario where human tear fluid bridges the electrodes of device $\mathrm{C}$ while attempting to measure the tissue impedance. As electric fields follow the path of least resistance, one would have to completely dry the conjunctiva prior to measurement to isolate the tissue impedance from of the tear fluid in vivo. If device $\mathrm{C}$ is not calibrated to measure impedance within the range of this manuscript, it should not return values within the expected human range on solutions known to represent tear osmolarity. It should be well out of range, yet that is not what was found. Device C provided random values across the full range of human tear osmolarity for each of the tested solutions. Either this is a failure in quality or failure in design of device C. Future studies could involve an impedance model constructed with far higher intrinsic resistance than the contrived tear solutions used in this study to investigate the values returned by device C. If the values are still within the human range, it means the device is incapable of distinguishing systems of different impedance, making the output suspect. If the values are out of range, it means the device is calibrated for the solutions tested here and it is simply too imprecise to be used in the clinic to usefully measure tear osmolarity.

\section{Conclusion}

In this randomized, masked, in vitro study, device A and device B performed similarly in their ability to accurately and precisely delineate the osmolarity of contrived tear solutions of known target values; device $\mathrm{C}$, however, demonstrated insufficient performance to precisely and accurately identify and delineate different osmolarity levels within the physiological range. Additional studies on human subjects would be required to compare performance in a clinical setting.

\section{Disclosure}

The study was funded by TearLab Corporation. The authors report no other conflicts of interest in this work.

\section{References}

1. International Dry Eye WorkShop, The definition and classification of dry eye disease. In: 2007 Report of the International Dry Eye Workshop (DEWS). Ocul Surf. 2007;5:75-92.

2. Tomlinson A, Khanal S, Ramaesh K, Diaper C, McFadyen A. Tear film osmolarity: determination of a referent for dry eye diagnosis. Invest Ophthalmol Vis Sci. 2006;47(10):4309-4315.

3. Sullivan BD, Whitmer D, Nichols KK, et al. An objective approach to dry eye disease severity. Invest Ophthalmol Vis Sci. 2010;51(12): 6125-6130.

4. Farris RL. Tear osmolarity - a new gold standard? Adv Exp Med Biol. 1994;350:495-503.

5. Versura P, Profazio V, Campos EC. Performance of tear osmolarity compared to previous diagnostic tests for dry eye diseases. Curr Eye Res. 2010;35(7):553-564.

6. Epitropoulos AT, Donnenfeld ED, Shah ZA, et al. Effect of oral reesterfied omega-3 nutritional supplementation on dry eyes. Cornea. 2016;35(9):1185-1191.

7. Deinema LA, Vingrys AJ, Wong CY, et al. A randomized, double-masked, placebo-controlled clinical trial of two forms of omega-3 supplements for treating dry eye disease. Ophthalmology. 2017;124(1):43-52.

8. Tomlinson A, Hair M, McFadyen A. Statistical approaches to assessing single and multiple outcome measures in dry eye therapy and diagnosis. Ocul Surf. 2013;11(4):267-284.

9. Versura P, Profazio V, Giannaccare G, et al. Discomfort symptoms reduction and ocular surface parameters recovery with artelac rebalance treatment in mild-moderate dry eye. Eur J Ophthalmol. 2013;23(4): 488-495.

10. Comez AT, Tufan HA, Kocabiyik O, Gencer B. Effects of lubricating agents with different osmolalities on tear osmolarity and other tear function tests in patients with dry eye. Curr Eye Res. 2013;38(11):1095-1103.

11. Liu H, Begley C, Chen M, et al. A link between tear instability and hyperosmolarity in dry eye. Invest Ophthalmol Vis Sci. 2009; 50(8):3671-3679.

12. Fortes MB, Diment BC, Di Felice U, et al. Tear fluid osmolarity as a potential marker of hydration status. Med Sci Sports Exerc. 2011;43(8): $1590-1597$. 
13. Jacobi C, Jacobi A, Kruse FE, Cursiefen C. Tear film osmolarity measurements in dry eye disease using electrical impedance technology. Cornea. 2011;30(12):1289-1292.

14. Lemp MA, Bron AJ, Baudouin C, et al. Tear osmolarity in the diagnosis and management of dry eye disease. Am J Ophthalmol. 2011;151(5): 792-798.e1.

15. US FDA k083184, TearLab Osmolarity System. April 23, 2009.

16. Hirata H, Mizerska K, Marfurt CF, Rosenblatt MI. Hyperosmolar tears induce functional and structural alterations of corneal nerves: electrophysiological and anatomical evidence toward neurotoxicity. Invest Ophthalmol Vis Sci. 2015;56(13):8125-8140.
17. TearLab Osmolarity Test Cards Instructions for Use, 930088 Rev G, 2015, TearLab Corporation.

18. Gokhale M, Stahl U, Jalbert I. In situ osmometry: validation and effect of sample collection technique. Optom Vis Sci. 2013;90(4):359-365.

19. Tomlinson A, McCann LC, Pearce EI. Comparison of human tear film osmolarity measured by electrical impedance and freezing point depression techniques. Cornea. 2010;29(9):1036-1041.

20. i-Pen Osmolarity System User Manual. I-Med Pharma Inc, 2016.

21. Pethig R. Dielectric properties of body tissues. Clin Phys Physiol Meas. 1987;8(Suppl A):5-12.
Clinical Ophthalmology

\section{Publish your work in this journal}

Clinical Ophthalmology is an international, peer-reviewed journal covering all subspecialties within ophthalmology. Key topics include: Optometry; Visual science; Pharmacology and drug therapy in eye diseases; Basic Sciences; Primary and Secondary eye care; Patient Safety and Quality of Care Improvements. This journal is indexed on

\section{Dovepress}

PubMed Central and CAS, and is the official journal of The Society of Clinical Ophthalmology (SCO). The manuscript management system is completely online and includes a very quick and fair peer-review system, which is all easy to use. Visit http://www.dovepress.com/ testimonials.php to read real quotes from published authors. 